\title{
Toward Alignment between Communities of Practice and Knowledge-Based Decision Support
}

\author{
Jason Nichols \\ Oklahoma State University \\ David Biros \\ Oklahoma State University \\ Mark Weiser \\ Oklahoma State University
}

Follow this and additional works at: https://commons.erau.edu/jdfs|

Part of the Computer Engineering Commons, Computer Law Commons, Electrical and Computer Engineering Commons, Forensic Science and Technology Commons, and the Information Security Commons

\section{Recommended Citation}

Nichols, Jason; Biros, David; and Weiser, Mark (2012) "Toward Alignment between Communities of Practice and Knowledge-Based Decision Support," Journal of Digital Forensics, Security and Law: Vol. 7 : No. 2 , Article 4. DOI: https://doi.org/10.15394/jdfsl.2012.1119

Available at: https://commons.erau.edu/jdfsl/vol7/iss2/4

This Article is brought to you for free and open access by

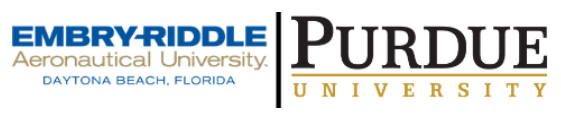
the Journals at Scholarly Commons. It has been accepted for inclusion in Journal of Digital Forensics, Security and Law by an authorized administrator of Scholarly Commons. For more information, please contact commons@erau.edu.

(c)ADFSL

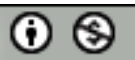




\title{
Toward Alignment between Communities of Practice and Knowledge-Based Decision Support
}

\author{
Jason Nichols, David Biros, Mark Weiser \\ Management Science and Information Systems \\ Spears School of Business \\ Oklahoma State University \\ Stillwater, OK 74078
}

\begin{abstract}
The National Repository of Digital Forensics Information (NRDFI) is a knowledge repository for law enforcement digital forensics investigators (LEDFI). Over six years, the NRDFI has undertaken significant design revisions in order to more closely align the architecture of the system with theory addressing motivation to share knowledge and communication within ego-centric groups and communities of practice. These revisions have been met with minimal change in usage patterns by LEDFI community members, calling into question the applicability of relevant theory when the domain for knowledge sharing activities expands beyond the confines of an individual organization to a community of practice. When considered alongside an empirical study that demonstrated a lack of generalizability for existing theory on motivators to share knowledge, a call for deeper investigation is clear. In the current study, researchers apply grounded theory methodology through interviews with members of the LEDFI community to discover aspects of community context that appear to position communities of practice along a continuum between process focus and knowledge focus. Findings suggest that these contextual categories impact a community's willingness to participate in various classes of knowledge support initiatives, and community positioning along these categories dictates prescription for design of knowledge based decision support systems beyond that which can be found in the current literature.
\end{abstract}

Keywords: grounded theory, decision support, communities of practice, knowledge management

\section{INTRODUCTION}

The Center for Telecommunications and Network Security (CTANS), a recognized National Security Agency Center of Excellence in Information Assurance Education (CAEIAE), has been developing, hosting, and continuously evolving web-based software to support law enforcement digital forensics investigators (LEDFI) via access to forensics resources and communication channels for the past 6 years. The cornerstone of this initiative has been the National Repository of Digital Forensics Information (NRDFI), a collaborative effort with the Defense Cyber Crime Center (DC3), which has evolved into the 
Digital Forensics Investigator Link (DFILink) over the past two years. DFILink is soon to receive additional innovations tailored to its LEDFI audience, and the manuscript herein is an account of recent grounded theory research efforts targeting the LEDFI community in order to form a baseline to match their needs with the resources and services contained within DFILink. More broadly, the grounded theory that is emerging from this study highlights critical characteristics of context for a knowledge-based decision support implementation that the current literature on motivating knowledge sharing appears to be lacking. In order to motivate the need for this grounded theory work, the following subsections briefly describe the theory-driven approaches to early NRDFI design, the evolution from NRDFI to DFILink, and replication of a prior empirical study that highlights the potential gap in theory as relates to motivators for knowledge sharing and actual system use.

\subsection{NRDFI}

The development of the NRDFI was guided by the theory of the ego-centric group and how these groups share knowledge and resources amongst one another in a community of practice (Jarvenpaa \& Majchrzak, 2005). Within an egocentric community of practice, experts are identified through interaction, knowledge remains primarily tacit, and informal communication mechanisms are used to transfer this knowledge from one participant to the other. The informality of knowledge transfer in this context can lead to local pockets of expertise as well as redundancy of effort across the broader community as a whole. In response to these weaknesses, the NRDFI was developed as a hub for knowledge transfer between local law enforcement communities. The NRDFI site was locked down so that only members of law enforcement were able to access content, and members were provided the ability to upload knowledge documents and tools that may have developed locally within their community, so that the broader law enforcement community of practice could utilize their contributions and reduce redundancy of efforts. The Defense Cyber Crime Center, a co-sponsor of the NRDFI initiative, provided a wealth of knowledge documents and tools in order to seed the system with content.

Response from the LEDFI community was positive, and membership to the NRDFI site quickly jumped to over 1000 users. However, the usage pattern for these members was almost exclusively unidirectional. LEDFI members would periodically log on, download a batch of tools and knowledge documents, and then not log on again until the knowledge content on the site was extensively refreshed. The mechanisms in place for local LEDFI communities to share their own knowledge and tools sat largely unused. From here, CTANS began to explore the literature with regards to motivating knowledge sharing, and began a re-design of NRDFI driven by the extant literature, and focused on promoting sharing within the LEDFI community through the NRDFI. 


\subsection{Motivating Knowledge Sharing and the DFILink}

DFILink is a redesign of NRDFI that shifts the focus of sharing within the community from formal knowledge documents and tools to informal discussion and collaboration surrounding existing documents and tools within the system. The same broad set of knowledge resources from NRDFI is available through DFILink, however the ability to discuss these resources has been given equal importance in the design of the system.

This shift in focus was driven primarily by two discoveries in the literature surrounding motivation for knowledge sharing: First, the primary motivators for sharing knowledge are intrinsic in nature (i.e. through positive feedback, a sense of community, and incremental praise). Second, these intrinsic motivators are more effective when the overhead for making a contribution is low (Bock \& Kim, 2002; Bock, Lee, Zmud, \& Kim, 2005). These two discoveries were taken from what appears to be the prevailing model in the literature for motivating knowledge sharing, and formed the backbone for a redesign strategy that emphasized the social aspect of participating in a community of practice. The ability to pose questions, make comments, and informally engage the community across all aspects of the system and the resources contained therein was underscored in the resulting transition to DFILink. Additionally, these informal communications mechanisms served to bring the system closer in alignment to theory for how egocentric groups actually communicate (Fisher, 2005). In short, DFILink was built to embody the best lessons from the literature with regards to motivating sharing and supporting communication within a community of practice.

However, two years after the transition, usage patterns for DFILink mirror that of its predecessor NRDFI. LEDFI members will log on to pull down resources, but rarely if ever upload and share their own or utilize the informal communications channels embedded within the system. Design based upon the prevailing theory surrounding motivating knowledge sharing within communities of practice appears to have had little-to-no impact on sharing within the LEDFI community itself. Empirical research performed by the investigators during the transition from NRDFI to DFILink further highlights the potential gap in the literature between the theory of motivating knowledge sharing and what can be observed in communities of practice such as LEDFI.

\subsection{Re-examining Motivation to Share Knowledge}

One of the preeminent works in the area of motivators to share knowledge examines the relative importance of intrinsic versus extrinsic motivators in the context of a broad sampling of asian firms (Bock, et al., 2005). The outcome of this study demonstrates that there is a strong link between intrinsic motivation and intention to share knowledge, and extrinsic motivators can actually serve as a demotivational factor in the long run. The literature has used this study as a foundation for further work (e.g. Chiu, Hsu, \& Wang, 2006; Hsu, Ju, Yen, \& Chang, 2007; Kankanhalli, Bernard, \& W., 2005), and the notion that intrinsic 
motivators drive the sharing of knowledge is widely held within the domain. The transition from NRDFI to DFILink adhered to this principle through the incorporation of social mechanisms for positive feedback and contribution through informal communications. Still, we were interested in the generalizability of the prior study to the context of egocentric groups and, more broadly, distributed communities of practice such as LEDFI. A replication of the study was performed with a sample of LEDFI members, and the results called into question the findings of the earlier work (Hass, et al., 2009).

In a community of practice such as LEDFI, the link between intrinsic motivation and intention to share knowledge was observed to be significantly weaker, and bordering on non-existent. Interestingly, while the link between extrinsic motivators and intention to share was no longer significantly negative as in the previous study, it too remained tenuous at best. In short, when the commonly accepted model of motivation to share knowledge was applied to the LEDFI community, neither intrinsic nor extrinsic motivators appeared to provide strong support for what would drive an LEDFI member to share their knowledge.

With this in mind, and coupled with the observation of stagnant usage patterns throughout the theory-driven transition from NRDFI to DFILink, the investigators noted a potential gap in the literature as relates to theory regarding willingness to share knowledge in a distributed community of practice. What follows is an account of the first round of grounded theory research regarding this gap, initial findings from interviews and a focus group with a sample of the LEDFI community, and a discussion of resulting prescription for knowledge-based decision support systems targeting communities of this nature.

\section{METHODOLOGY}

The investigators selected grounded theory, a specifically qualitative approach, based upon their experience applying the results of existing quantitative studies to the design of DFILink and meeting minimal success in their objectives, as well as the discovery of contradictory findings when applying an accepted quantitative model to the context of the LEDFI community. Grounded theory is markedly process-driven in its focus (Strauss \& Corbin, 1998), and avoids a priori assumptions regarding the processes underlying the phenomena of interest. This is in contrast to a deductive quantitative approach, and is appropriate in scenarios where the accepted theory in a domain is unable to adequately capture behaviors of practitioners in the field. The process-focus of grounded theory allows the researcher to examine directly what occurs in practice, and the inductive nature of the methodology supports contributions to existing theory that can more adequately capture and explain behavior in the field.

Interviews were carried out at the 2012 Department of Defense Cyber Crimes Conference in Atlanta, in order to purposefully sample members of the LEDFI community of various positions within their respective departments. Our initial five interview subjects spanned the range of positions from direct forensics 
investigators to mid-level forensic lab managers to higher-level departmental management. Early interviews were purposefully unstructured and open ended, focusing on the identification of patterns in process for applying knowledge in order to complete digital forensics tasks. Nightly coding of interview notes took place in accordance with guidelines for grounded theory (Glaser, 1978), which followed the pattern of initial "open coding" to first identify key concepts or dimensions (referred to as categories), and subsequent "selective coding" once uniformities in the interview notes were revealed.

As the resulting categories became saturated, interviews became more tightly structured in order to explore these categories further, until no new properties emerged from additional investigation. A total of 20 interviews were conducted in this first round of investigation, which is within guidelines for the volume of interviews recommended to begin to answer research questions through grounded theory (McCracken, 1988). Subsequently, a summary of the findings and resulting implications for practice was shared with a focus group comprised of an additional 10 LEDFI members. Glaser (1978, 1992, 2001) emphasizes the following criteria for assessing rigor and validity of grounded theory studies: fit, relevance, workability, modifiability, parsimony and scope. Table 1 is provided as a summary of the investigators' effort within this framework (in line with similar grounded theory studies e.g. Mello, Stank, \& Esper, 2008).

Table 1. An assessment of rigor for grounded theory

\begin{tabular}{|c|c|c|}
\hline Criteria & Definition & Evidence \\
\hline Fit & $\begin{array}{l}\text { Do the findings match } \\
\text { the conditions within } \\
\text { the domain under } \\
\text { investigation? }\end{array}$ & $\begin{array}{l}\text { - Findings were drawn based on } \\
\text { patterns across all interviews } \\
\text { Initial theory and implications } \\
\text { were presented and validated } \\
\text { by a focus group of } \\
\text { community members }\end{array}$ \\
\hline Relevance & $\begin{array}{l}\text { Does the outcome } \\
\text { contribute to solving a } \\
\text { real problem in } \\
\text { practice? Do the results } \\
\text { contribute to existing } \\
\text { theory through a } \\
\text { broader understanding? }\end{array}$ & $\begin{array}{l}\text { Findings from the study } \\
\text { directly impact the evolution } \\
\text { of an existing artifact within } \\
\text { the community, in a fashion } \\
\text { validated by community } \\
\text { members. } \\
\text { Continuing research seeks to } \\
\text { position these findings within } \\
\text { the knowledge management, } \\
\text { decision support, and } \\
\text { task/technology fit domains. }\end{array}$ \\
\hline Workability & $\begin{array}{l}\text { Do the findings directly } \\
\text { address what is }\end{array}$ & $\begin{array}{l}\text { Early theory derived from } \\
\text { interviews was shared and } \\
\text { confirmed by participants of }\end{array}$ \\
\hline
\end{tabular}




\begin{tabular}{|c|c|c|}
\hline & $\begin{array}{l}\text { happening within the } \\
\text { domain? }\end{array}$ & the study. \\
\hline Modifiability & $\begin{array}{l}\text { Can contradictions be } \\
\text { included in the } \\
\text { emerging theory } \\
\text { through modification? }\end{array}$ & $\begin{array}{l}\text { The emergent categories from } \\
\text { this first round of inquiry will } \\
\text { tested and augmented as } \\
\text { necessary through continuing } \\
\text { theoretical sampling and data } \\
\text { collection. }\end{array}$ \\
\hline Parsimony & $\begin{array}{l}\text { Is the theory limited to } \\
\text { a minimum of } \\
\text { categories needed to } \\
\text { explain the } \\
\text { phenomenon? }\end{array}$ & $\begin{array}{l}\text { - Selective coding was applied } \\
\text { to the open-coded data in } \\
\text { order to reduce the number of } \\
\text { categories while maintaining } \\
\text { explanatory coverage across } \\
\text { all cases in the study. }\end{array}$ \\
\hline Scope & $\begin{array}{l}\text { Is the theory flexible } \\
\text { enough to provide } \\
\text { insight into a variety of } \\
\text { situations? }\end{array}$ & $\begin{array}{l}\text { Scope for the categories } \\
\text { discovered in this first round } \\
\text { of data collection will be } \\
\text { examined through continuing } \\
\text { theoretical sampling of a } \\
\text { broader range of communities } \\
\text { of practice. }\end{array}$ \\
\hline
\end{tabular}

\section{FINDINGS}

An analysis of the data collected from the interviews revealed three critical categories that impact the way in which a LEDFI member is willing to participate in knowledge sharing activities: organizational structure, task complexity, and workload. These characteristics were a recurring theme across the interviews conducted, and revealed themselves as key aspects driving the processes and mechanisms LEDFI members selected when either gathering or sharing knowledge within the community. Across each category, the impact of the category on selection of knowledge sharing mechanisms was explored. Each category is addressed individually below. The result is a reliance on local knowledge silos and existing informal communications mechanisms almost exclusively within the community of practice.

\subsection{Organizational Structure}

LEDFI members exist in a rigid organizational context. From the interviews, this exposes itself in a number of different ways. First, due to the legal requirements surrounding the validity of their work, investigators are encouraged to maintain an autonomous core of knowledge and tools within their own departments. These knowledge cores are the first targets of inquiry when performing an activity that requires support. Introduction of external sources for knowledge and tools often 
requires the approval of organizational management, and is frequently limited to knowledge gathering rather than knowledge sharing. Further, there are frequently strict guidelines regarding the sharing of internally developed resources, which limits the participation of members in formal external knowledge sharing efforts.

Members within this rigid organizational context prefer to offer support to their community colleagues individually, informally, and on a case-by-case basis. While the community as a whole recognizes the potential for inefficiency in this approach, members are often constrained by the rigidity of their organizational boundaries and procedures from availing their knowledge cores to the broader LEDFI community in general. If identified as an expert and approached individually, however, they are likely to be willing to share their expertise with an LEDFI colleague on a one-to-one basis.

\subsection{Task Complexity}

Subjects uniformly identified an 80-20 rule with respect to the complexity of the tasks they perform. $80 \%$ of the time, their tasks are routine and require little to no knowledge support for completion. The other $20 \%$ of their tasks require knowledge support, but that support can be achieved through access to their department's internal knowledge core or through informal requests to the broader community by utilizing existing communication channels. They recognize that there may exist better tools and solutions than what they can find within their own knowledge cores or through informal requests for assistance, but the relatively low frequency for which they require external assistance acts as a disincentive for exploring, becoming familiar with, and investing time on external formal knowledge repositories. They identify a trade-off between the time and effort required to become familiar with and actively use these external resources, and the amount of time and effort such familiarity would potentially save them in their daily operations. For them, considering how little they find themselves in need of knowledge support, the tradeoff does not favor active involvement in external formal knowledge repositories.

\subsection{Workload}

The vast majority of subjects interviewed reported a significant backlog of work within their department. Following the 80-20 rule identified regarding their tasks, this translated for the subjects into heavy time pressure to apply their existing expertise towards routine tasks as quickly as possible in order to work down the backlog. When facing a task that requires knowledge support, this time pressure influences their preference to use existing informal and asynchronous communications channels to seek assistance, as they can then move on to backlogged routine tasks while they wait for a response. In essence, the backlog of work they often face means that, even if they wanted to become active members of an external knowledge community and gain expertise to the resources available therein, they are forced to repurpose the time that this would take as time to continue working down their backlog of routine tasks while they wait for 
informal support.

A profile of the LEDFI community across these categories is presented in figure 1. Through the interviews performed, these categories emerged as the primary influence within the community over how knowledge is shared and discovered amongst participants. Based upon their positioning along these categories, LEDFI members exhibit a strong preference for locally developed knowledge cores and existing informal communication channels when seeking support. Virtually all subjects noted listservs as the external communication channel of choice when seeking support from the broader community. They also recognized and were willing to accept the potential for inefficiency in knowledge discovery through this communications channel. For them, the tradeoff in effort required to become active users in a more structured knowledge management approach did not support the potential gains in process improvement for their infrequent knowledge-intensive tasks. Put simply, they recognize there may be valuable resources available externally. However, due to their rigid organizational structure, relatively routine tasks, and heightened workload, they are willing to forego these resources in favor of support mechanisms that fold seamlessly into their existing workflow.

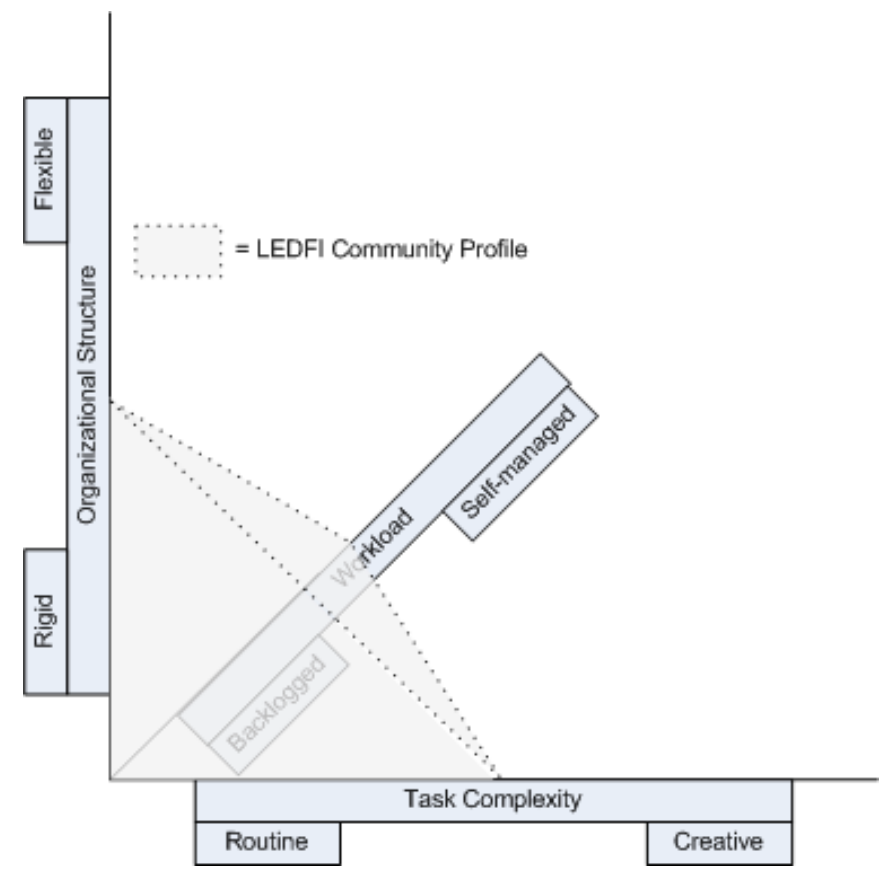

Figure 1. LEDFI Community Profile

\section{DISCUSSION}

\subsection{Implications for Theory}

This first round of data collection supports a broader research objective to identify 
and examine communities of practice that vary along the discovered categories of structure, complexity, and workload. Based on findings from our work with LEDFI, it is proposed that communities of practice experience contextual pressures related to knowledge sharing that set them apart from communities within a formal organizational boundary. For communities of practice, the link between intrinsic reward and active knowledge sharing may be moderated by the communities' positioning along these three contextual dimensions. Additional evidence of this moderation affect will serve to broaden the organizational climate construct in the motivation literature to include external influences, rather than the current internal focus on fairness, affiliation, and innovativeness (Bock, et al., 2005). Our continued efforts will seek to expand the predominant model on motivation to share knowledge, so that the model fits in the context of communities of practice as well as in the context of individual organizations.

Further, the work done here suggests that a community's position along these dimensions may dictate the degree to which knowledge management efforts must either conform to existing workflows and processes within the community, or are free to influence the workflows and processes themselves. This tradeoff is represented in figure 2. Continued work to explore this tradeoff within a broader set of diverse communities of practice seeks to contribute to the literature related to task/technology fit (Goodhue, 1995; Goodhue \& Thompson, 1995). We find partial alignment with existing research in this domain that maps task characteristics to appropriate technology support mechanisms (Zigurs \& Buckland, 1998). However, rather than focus on the capabilities availed through the technology, we will continue to focus on the tradeoff between technology support that can achieve the greatest hypothetical advantage, and technology support that will actually be used. In some ways, then, we are looking to broaden the focus from task/technology fit to community/technology fit. The initial finding here is that the best knowledge management option is not the one with the greatest performance potential, but the one that will actually be used. 


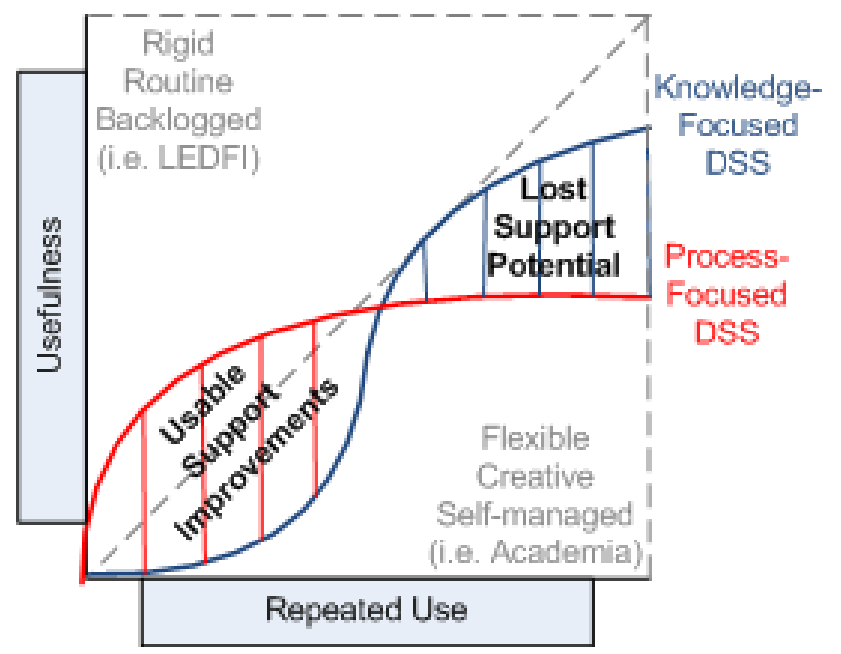

Figure 2. Tradeoff between process vs. knowledge focused support

For example, NRDFI and DFILink were designed to offer a tight integration between resource discovery and the sharing of knowledge related to these resources by way of community involvement within the site itself. Through this tight coupling of centralized discovery and sharing, formal knowledge resources can be surrounded by informal, community-driven knowledge that incrementally increases the value of the resource over time. However, the potential benefit of this tightly coupled architecture assumes that community participants are willing to integrate use of the knowledge repository within their existing workflows. As we have discovered here, LEDFI simply is not. The result is a powerful knowledge management solution, engineered within the guidelines of best practice from the literature, recognized by the community as a source of valuable content, that by in large sits on the shelf unused. What the LEDFI community has shared with us on this issue is that rigid organizational structure, an abundance of routine tasks, and a heavy workload all contribute to a context where knowledge support must be folded into existing workflows if it is to be utilized. This seamless mapping into existing workflows takes priority over the relative power of the knowledge management capabilities available. In other words, the best knowledge management solution is the one that gets used.

\subsection{Implications for Practice}

While we continue to explore the categories that influence communities of practice along the process-centric/knowledge-centric continuum, the message is clear for a process-centric community such as LEDFI: seamless integration of knowledge support into existing workflows and communications channels is a requirement for knowledge discovery and use. Therefore, primary methods of communication within the community must be identified, and knowledge management technology must evolve to take an active role within these 
communications channels. For the LEDFI community, listservs represent a primary form of communication when members seek assistance outside of their organization. Taking cues from agent-based decision support research (Bui \& Lee, 1999), the next evolution of DFILink will be the development of a listserv agent that matches requests from users on the listserv to resources that may prove useful. A sequence diagram for listserv agent interaction is presented below in figure 3 .

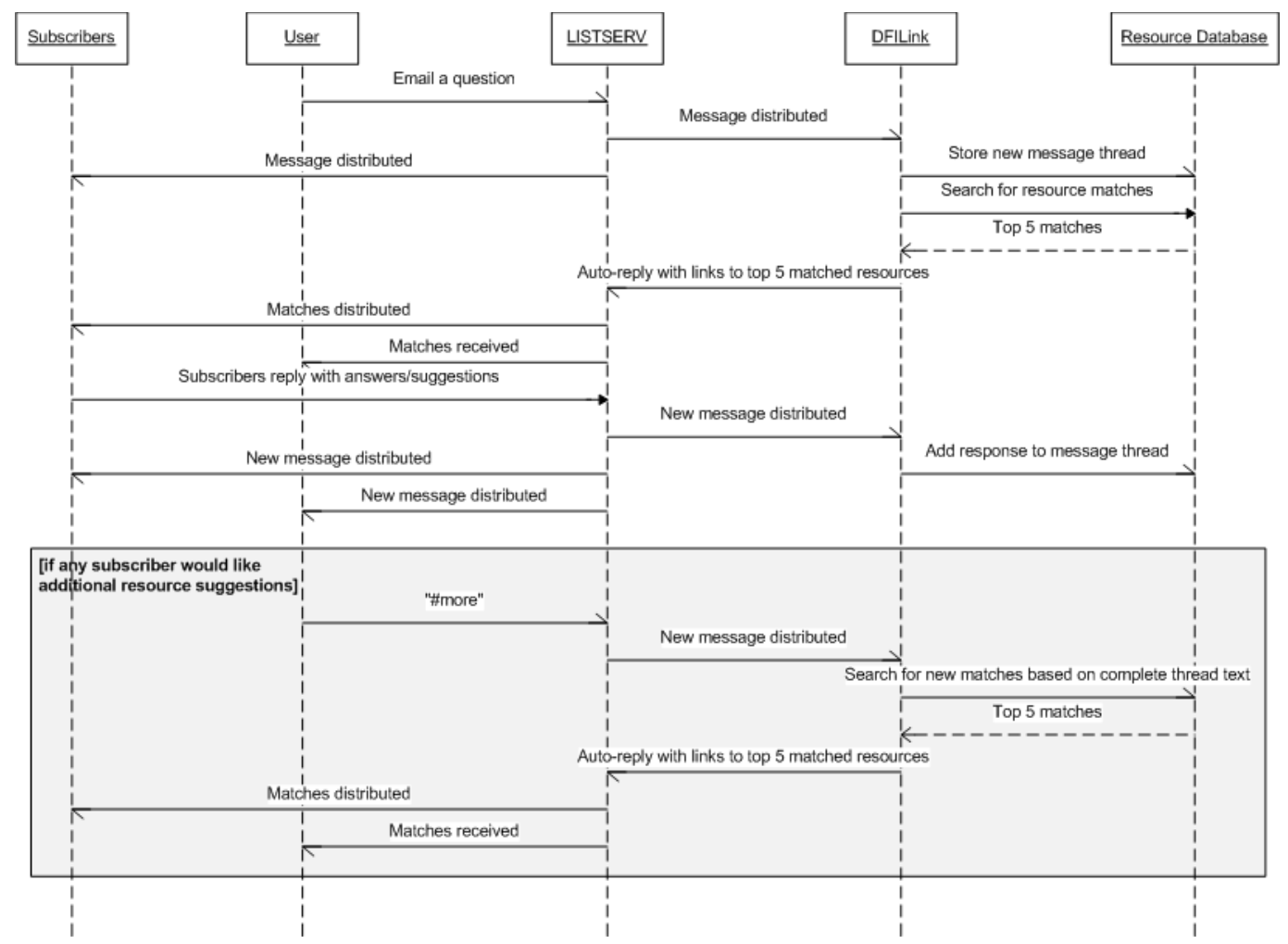

Figure 3. Sequence for user/agent interaction via listservs

The DFILink listserv agent will be designed so that it can subscribe and contribute to not only a specific DFILink listserv, but also any partnering listserv from the LEDFI community that wishes to participate. The agent will monitor traffic on the listservs, and respond with resource matches based on the content of the initial question posted. As the conversation thread continues, the agent will continue to monitor traffic so that, if any listserv member would like to interact further with the agent, a short list of hash-tag command options are at their disposal and can be sent as a reply to the listserv itself. For instance, if a participant would like to see additional resource matches, they can reply with "\#more", and the agent will perform an additional search based on not only the text from the original posting, but all subsequent postings in the email thread. Further, these email threads will be maintained as resources within DFILink and 
the agent will potentially include them as matches to future inquiries. In this fashion, the primary communications channel for the community is strengthened by the inclusion of relevant knowledge resources, maintains a long-term memory of tacit knowledge transfer, and does not require any adaptation of existing workflows and processes on the part of the community members.

\section{CONCLUSION}

Theory regarding motivation for knowledge sharing appears to lack fit in the context of communities of practice. The research presented here applied a grounded theory methodology in the examination of one such community: law enforcement digital forensics investigators. The results point towards three community characteristics, organizational rigidity, task complexity, and participant workload, as determinants for a community's preference between process-centric versus knowledge-centric decision support. Continuing research will explore the impact of these characteristics within a broader set of communities of practice, with the aim to contribute to broader theory for motivation to share knowledge as well as task/technology fit in the context of a community of practice. However, the findings of this study directly impact the design of successful knowledge-based decision support technologies for communities that share the LEDFI profile. Technologies must integrate seamlessly into existing community workflows and processes, even at the expense of greater knowledge management capability. For a process-centric community, knowledge management capabilities will be ignored otherwise.

\section{REFERENCES}

Bock, G., \& Kim, Y. (2002). Breaking the Myths of Rewards: An Exploratory Study of Attitudes About Knowledge-Sharing. Information Resources Management Journal, 15(2), 14.

Bock, G., Lee, J., Zmud, R., \& Kim, Y. (2005). Behavioral Intention Formation in Knowledge Sharing: Examining the Roles of Extrinsic Motivators, Social-Psychological Forces, and Organizational Climate. MIS Quarterly, 29(1), 87.

Bui, T., \& Lee, J. (1999). An Agent-Based Framework for Building Decision Support Systems. Decision Support Systems, 25(3), 225.

Chiu, C., Hsu, M., \& Wang, E. (2006). Understanding Knowledge Sharing in Virtual Communities: An Integration of Social Capital and Social Cognitive Theories. Decision Support Systems, 42(3), 1872.

Fisher, D. (2005). Using Egocentric Networks to Understand Communication. Internet Computing, IEEE, 9(5), 20.

Glaser, B. (1978). Theoretical Sensitivity: Advances in the Methodology of 
Grounded Theory. Mill Valley, CA: The Sociology Press.

Glaser, B. (1992). Basics of Grounded Theory Analysis. Mill Valley, CA.: Sociology Press.

Glaser, B. (2001). The Grounded Theory Perspective: Conceptualization Contrasted with Description. Mill Valley, CA.: Sociology Press.

Goodhue, D. (1995). Understanding User Evaluations of Information Systems. Management Science, 41(12), 1827.

Goodhue, D., \& Thompson, R. (1995). Task-Technology Fit and Individual Performance. MIS Quarterly, 19(2), 213.

Hass, M., Nichols, J., Biros, D., Weiser, M., Burkman, J., \& Thomas, J. (2009). Motivating Knowledge Sharing in Diverse Organizational Contexts: An Argument for Reopening the Intrinsic vs. Extrinsic Debate. Paper presented at the AMCIS 2009 Proceedings.

Hsu, M., Ju, T., Yen, C., \& Chang, C. (2007). Knowledge Sharing Behavior in Virtual Communities: The Relationship Between Trust, Self-Efficacy, and Outcome Expectations. International Journal of Human-Computer Studies, 65(2), 153.

Jarvenpaa, S., \& Majchrzak, A. (2005). Developing Individuals' Transactive Memories of their Ego-Centric Networks to Mitigate Risks of Knowledge Sharing: The Case of Professionals Protecting CyberSecurity. Paper presented at the Proceedings of the Twenty-Sixth International Conference on Information Systems.

Kankanhalli, A., Bernard, C., \& W., K.-K. (2005). Contributing Knowledge to Electronic Knowledge Repositories: An Emperical Investigation. MIS Quarterly, 29(1), 113.

McCracken, G. (1988). The Long Interview. Thousand Oaks, CA.: Sage Publications.

Mello, J., Stank, T., \& Esper, T. (2008). A Model of Logistics Outsourcing Strategy. Transportation Journal, 47(4), 21.

Strauss, A., \& Corbin, J. (1998). Basics of Qualitative Research: Techniques and Procedures for Developing Grounded Theory. Thousand Oaks, CA: Sage Publications.

Zigurs, I., \& Buckland, B. (1998). A Theory of Task/Technology Fit and Group Support Systems Effectiveness. MIS Quarterly, 22(3), 313. 
Journal of Digital Forensics, Security and Law, Vol. 7(2) 